\title{
Leaf area determinations in sorghum and maize by the length-width method
}

\author{
H. van Arkel \\ UNDP/FAO Kenya Sorghum and Millets Development Project, P.O. Box 1275, \\ Nakuru, Kenya
}

Accepted: 1 October 1977

Key words: leaf area measurements, leaf area index, length-width method, sorghum, maize

\section{Summary}

Five plant population trials were carried out over 1974 and 1975 with 5 different sorghum and 4 different maize cultivars. Each trial was sample harvested several times during the growing period. Of 6080 leaves the leaf area was carefully determined and related to its length and width. By regression calculations an examination was made regarding the construction of the best calibration lines for the estimation of the product of length and width from leaf area. Plant population had no significant effect on the regressions. Drawing the regression lines through the origin was sometimes statistically rejected but if the regression lines were forced through the origin in spite of this, the loss of precision was very small. It is therefore concluded that forcing the regression lines through the origin involves an acceptable estimation error. The resulting regression lines which were established separately for each cultivar and harvest proved to estimate the leaf area accurately. The values of the regression coefficients varied between 0.65 and 0.77 . The lowest correlation coefficient was 0.968 , but $55 \%$ of all correlation coefficients was above 0.990 . If data from different harvests were pooled (although not allowable statistically) the highest mean error of estimation of leaf area at any harvesting time was $8.5 \%$.

\section{Introduction}

The leaf area index (LAI) is an important characteristic for the study of plant growing processes, because the leaf area which is photosynthetically active is the originator of all plant growth. Several methods of measuring leaf area have been developed during the past few decades some of which require sophisticated tools and/or leaf removal from the plants. Well known methods include the use of photoelectric cells, planimeter of sensitized photopaper. Other methods of older origin can often be carried out with less expensive equipment. The 'matching method' involves placing leaves on pieces of cardboard of known area cut to the shape of the 


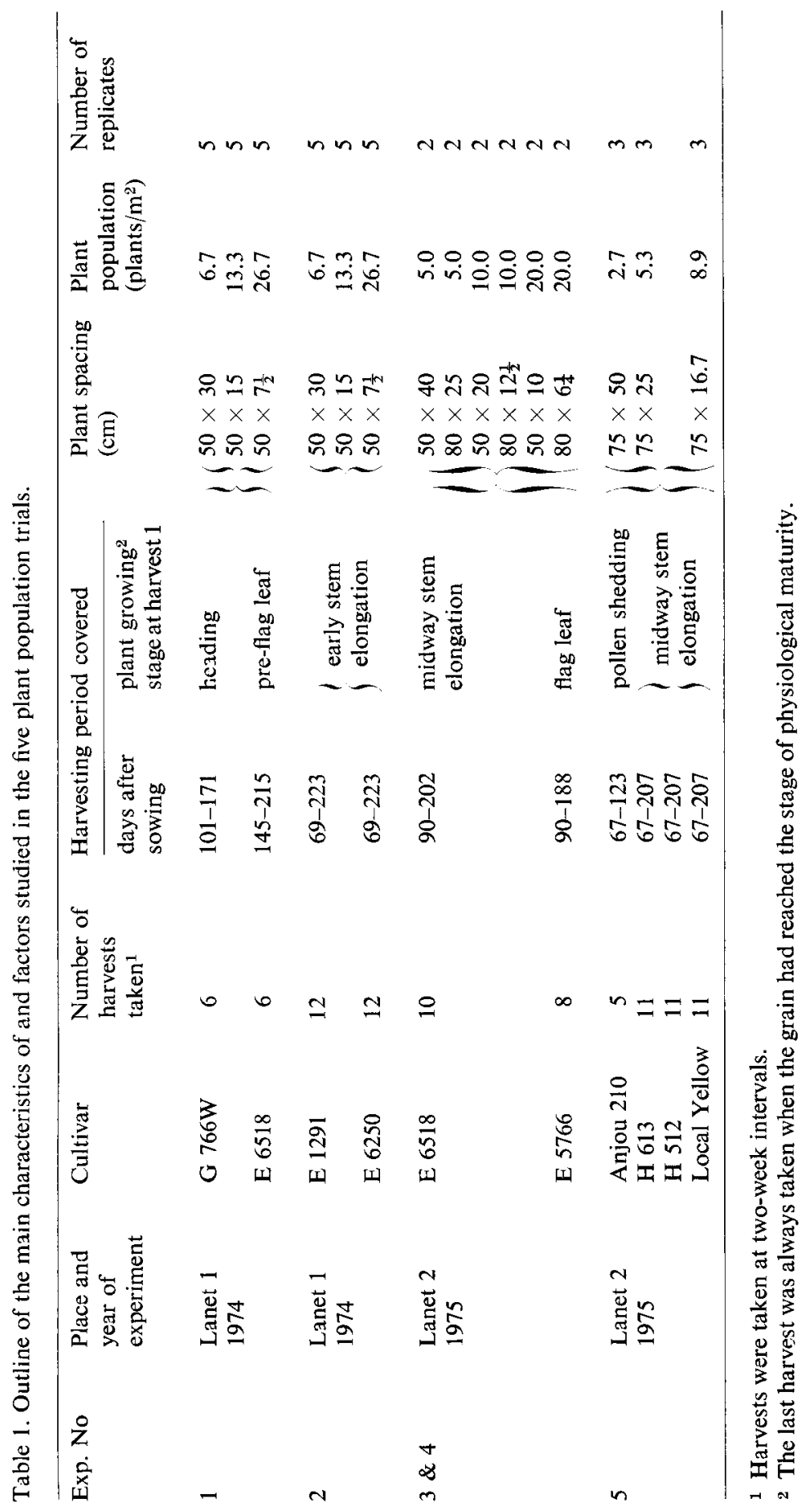

Neth. J. agric. Sci. 26 (1978) 
leaves (Darrow, 1932). Watson (1937) discussed the method of estimating leaf area on the basis of leaf weight. Linear measurements to estimate leaf area on the basis of regression techniques have been popular because they allow the leaves to remain intact. The leaf area is usually estimated as

$$
A=K_{1}+K_{2}(L \times W)
$$

where $L$ is the maximum length and $W$ is the maximum width of a leaf and $K_{1}$ and $\mathrm{K}_{2}$ are constants, dependent on crop. This method has been tested for e.g. beans (Davis, 1940), rice (Palaniswamy \& Gomez, 1974), cassava (Spencer, 1962) and castor (Jani \& Misra, 1966). For maize the method was first described by Montgomery (1911), and for sorghum it was reported by Stickler et al. (1961) who both found that $K_{1}$ may be assumed to be zero and $K_{2}$ equal to 0.75 . The main objectives of the present study were to test the suitability and accuracy of the method for some sorghum and maize cultivars of different origin grown under tropical highland conditions and to study the effects of harvesting date and plant population.

\section{Materials and methods}

\section{Field experiments}

Five plant spacing trials were carried out during 1974 and 1975 (Table 1). All plots were sample harvested several times during the growing season at two weeks intervals. All trials were carried out at the experimental farm of the Beef Research Station near Nakuru, where facilities were provided by the Kenya Government. The characteristics of the actual experimental fields have been described in a previous paper (van Arkel, 1978). Of the two sites described, the one with poor soil characteristics and lower rainfall was used for the trials 1 and 2, whereas the remaining three trials, all carried out in 1975 , were conducted at the better trial site.

The genetical characteristics of the materials used is briefly described in Table 2, while the expected yield performance of the high-altitude sorghums and the Kenya maize hybrids is given in more detail in a previous paper (van Arkel, 1977). Each of the experiments was sown immediately after the onset of the rainy season at

Table 2. Characteristics and origin of the cultivars used in the plant population experiments.

\begin{tabular}{ll}
\hline Cultivar & Brief description of characteristics and origin \\
G $766 \mathrm{~W}$ & American lowland dwarfed grain sorghum hybrid \\
E 6518 & high-altitude, cold-tolerant tall forage type sorghum from Ethiopian origin \\
E 1291 & high-altitude, cold-tolerant relatively short grain type sorghum from Ugandan origin \\
E 6250 & high-altitude, cold-tolerant forage type sorghum, yield-wise similar to E 6518 but \\
& more tillering; Ethiopian origin \\
E 5766 & high-altitude, cold-tolerant sorghum similar to E 1291 but taller; Ugandan origin \\
H 613 & widely used, high-yielding Kenyan maize hybrid, relatively late maturing \\
H 512 & as H 613 above but slightly earlier maturing \\
Local Yellow & maize cultivar selected from local material \\
Anjou 210 & maize hybrid with a high crop index originating from the temperate areas of maritime \\
& Europe
\end{tabular}


approximately three times the required plant density, and thinned back after plant establishment.

All trials were designed as complete blocks with all treatments represented in each block and therefore the number of replications (Table 1) is the same as the number of blocks. The width of each plot was chosen in such a way that nine rows were allowed of which two rows on each side acted as border rows, leaving five usable sampling rows. The length of each plot was established by taking two plants for each row and for each harvest and allowing two guard plants between each harvest. The number of plants was multiplied by the plant distance and the result thus obtained was doubled to allow for contingencies. At each harvest ten plants were cut from each plot as close to the ground as possible and taken to the laboratory for analysis.

\section{Leaf area estimation}

The leaf blades were removed from the stem ( + leaf sheath) and their maximum length and largest width were recorded. The leaf blades were roughly divided into five size groups and out of each group one leaf was sampled at random. The five leaves were carefully traced onto graphing paper which was then cut out and the weight of the cut-out was taken immediately and converted to leaf area.

Prior to this the relation between the area of the graphing paper and its weight was computed in the following manner: 45 pieces of graph paper of varying size in the range $5-700 \mathrm{~cm}^{2}$ were taken from each of 10 rolls of paper. The area of each piece was carefully measured and the corresponding weight recorded to the nearest $0.1 \mathrm{mg}$ five times at intervals of 2-3 weeks. The correlation coefficient between the 45 data points of any roll of paper at any one time was never less than 0.992 . The error of estimation $(\mathrm{P}<0.95)$ for the mean value of $\mathrm{X}$ was always within $1.3 \%$ of the mean value of $\mathrm{Y}$. Combining the data points of all 10 rolls of graph paper at any one time never showed a correlation coefficient less than 0.980. Combining the data points from all five times of weighing reduced the correlation coefficient considerably $(\mathrm{r}=0.928)$.

It seems likely that the graph paper is hygroscopic and its weight varied with air humidity. Henceforth it was decided that weighing of cut-out graph paper was sufficiently reliable for the estimation of area, as long as the regression of weight on area was established on the same day that the weight of the traced leaf-shaped paper pieces was determined. This was done by weighing the whole roll of graph paper of known area on the morning of sampling. The area per weight thus established varied between 92.32 and $94.87 \mathrm{~cm}^{2} / \mathrm{g}$.

\section{Statistical procedure}

The regression lines to be established will be used as calibration lines to estimate leaf areas from the measured length $\times$ width $(\mathrm{L} \times \mathrm{W})$. It is important to realize that, therefore, these calibration lines are established by computing the regression of $(\mathrm{L} \times \mathrm{W})$ on known area, and not the other way round. From each field plot such a regression line was calculated at each harvest on the basis of 5 points ( $=5$ leaves). It was then examined if it was permissible to take al leaves from all replicates to- 
Table 3. Residual sums of squares of the regression calculations resulting from data of the maize hybrid Anjou $210 ; D_{\mathbf{i}}=$ plant population; $\mathbf{R}_{\mathbf{i}}=$ replicate number.

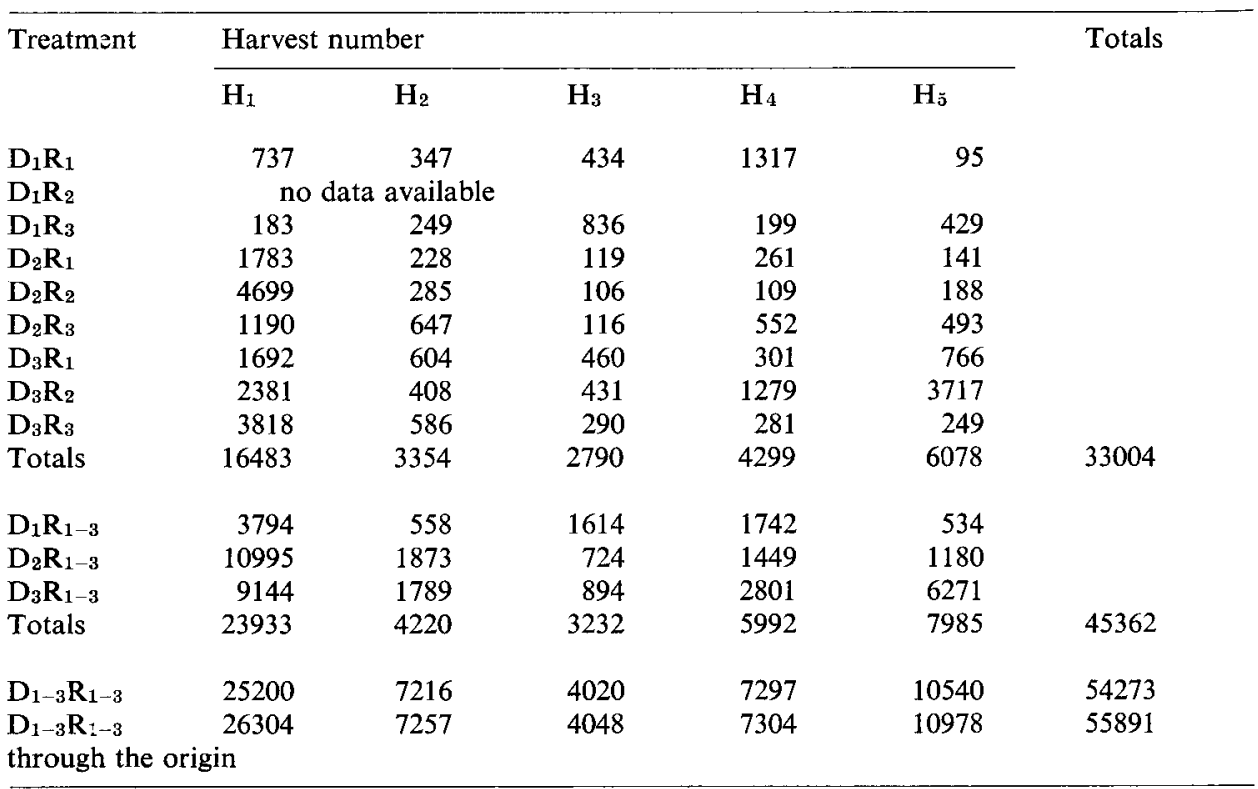

gether into one common regression line for each treatment. This was done by applying the following technique which is exemplified by using part of the data of the maize trial (Experiment No 5). At each harvesting date 4 maize cultivars, each planted at 3 different populations, are sampled. Each of these 12 treatments is replicated three times and consequently 36 regression lines at each harvesting date were obtained. From each treatment there are three regression lines each based on five points $(=$ leaves). The 12 regression lines based on all 15 leaves were calculated as well. Table 3 shows the residual sums of squares of the above regression calculations for 'Anjou 210'. If, for example, we now want to test whether at harvest 3 , the three replicates of plant population 2 may be described by a common line, the F statistic is computed as follows:

$$
\mathrm{F}_{9}^{4}=\frac{724-(119+106+116)) / 4}{(119+106+116) / 9}=2.53
$$

which does not exceed the tabulated $F$ value $(P<0.05)$ and hence $H_{0}$ is not rejected: the three replicate regression lines can be considered as identical. Since we are not interested in the validity per individual treatment, but rather in the validity of a more generally applicable principle, the actual $F$ values used in this paper were computed as an average per cultivar, combining all harvests and population. For the example chosen, the computed $\mathrm{F}$ statistic:

$$
F_{(120)}^{(170-120)}=F_{120}^{50}=\frac{(45362-33004) / 50}{33004 / 120}=0.90
$$


does not exceed the significant level at $\mathrm{P}<0.05$ and it may be concluded that for 'Anjou 210' replicates can be pooled.

Where $\mathrm{H}_{0}$ is not rejected the next step was to examine whether it is permissible to take the leaves of the different plant populations together in one common regression line per cultivar per harvest. This is done in a fashion similar to the calculations above. In the example of the 'Anjou 210' the test statistic becomes:

$$
F_{(120)}^{(190-170)}=F_{120}^{20}=\frac{(54273-45362) / 20}{33004 / 120}=1.62
$$

The minimum $\mathrm{F}$ value for significant treatment differences is $1.66(\mathrm{P}<0.05)$ and therefore the calculations show that the regression lines from the different plant populations may be pooled.

For those cultivars where it proved permissible to take the populations together, the next step was to test whether it is possible to work with one common regression line for all harvests. When all 200 leaves of 'Anjou 210' are brought together in one regression model the residual sums of squares are computed at 84275 . Hence the F value becomes:

$$
\mathrm{F}_{(120)}^{(198-190)}=\mathrm{F}_{120}^{8}=\frac{(84275-54273) / 8}{33004 / 120}=13.64
$$

and $\mathrm{H}_{0}$ is rejected.

At the point where further 'pooling' is rejected, it was examined whether the regression line can be drawn through the origin. Again the F statistic was employed and again it was examined to see whether the increase in residual sums of squares (i.e. unexplained error) due to the modification exceeds the critical level (Steel \& Torrie, 1960). Therefore, if harvest 1 is used as an example,

$$
F_{38}^{1}=\frac{(26304-25200) / 1}{(25200) / 38}=1.66
$$

it is clear that drawing the regression through the origin is not rejected.

\section{Results}

It was calculated that for all cultivars used in this study except one it was permissible to take together the leaves of replicates into common regression lines, which are specific for harvest, plant population and cultivar. This is demonstrated by the data in Table 4 where it is shown that, with the exception of ' $\mathrm{G} 766 \mathrm{~W}$ ', none of the computed $F$ values exceeded the critical level. It also appeared that plant population (and plant spacing for Experiments 2 and 3) did not contribute significantly to the variability between regressions and therefore it was allowed to pool data from the three plant populations studied into common regressions which are specific for harvest and cultivar only. The exception was the American hybrid ' $G$ 766W' which showed highly significant differences for plant populations. This is possibly so because ' $\mathrm{G} 766 \mathrm{~W}$ ' was of exotic origin and was not adapted to Kenyan conditions. This caused the cultivar to be heavily affected by leaf diseases (mainly blight, 
H. VAN ARKEL

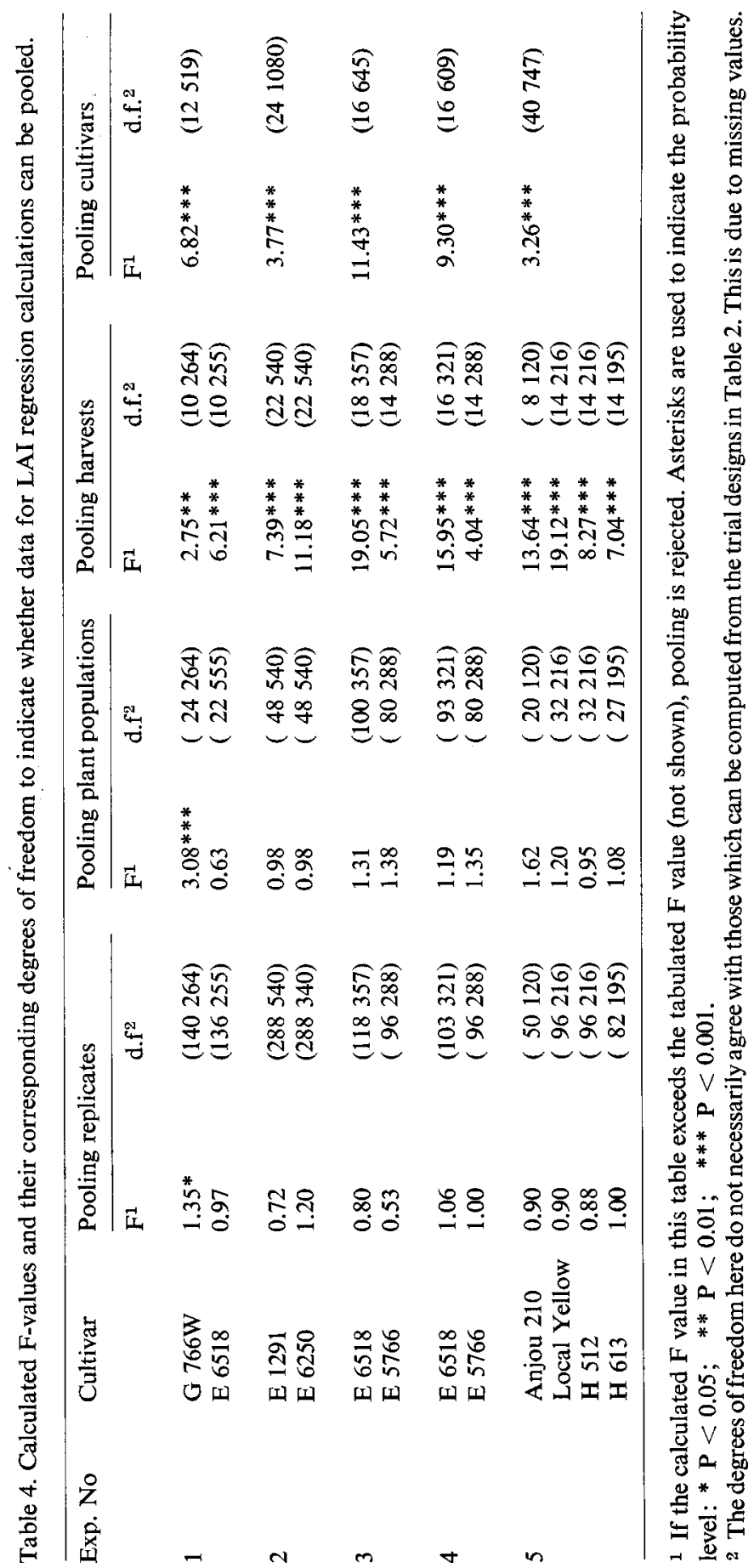


Helminthosporium turcicum) which resulted in very irregularly shaped leaves.

At this point it was possible to attempt either to pool all harvests within one cultivar, or to pool cultivars per harvest. In all instances this was statistically rejected because the increase of sums of squares exceeded the critical level considerably (Table 4).

At the next step, where it was examined to see whether regression lines could be drawn through the origin, the results were highly variable. In 72 cases it was permissible to draw the regression through the origin, but in 28 cases an intercept was required. The two types of regressions could not be related to any factor studied.

Clearly, future use of the leaf measurement method discussed in this paper would be made easier if we could decide on a generally applicable type of regression line, either with or without an intercept. Therefore it was examined to see what the effect on accuracy would be if all regression lines were drawn through the origin. This can be done in two ways. Firstly, examine the effect on the correlation coefficient and its related 'factor of determination' $\left(=r^{2} \times 100\right)$ or secondly, study the effect on the confidence belt around the regression lines. In the last case, the size of the standard error of predicted Ys ( = length $\times$ width) at the point of the mean value for $\mathrm{X}(=$ area) was used as a basis for comparison. This standard error taken as a percentage of the predicted value of $\mathrm{Y}$ can be called the coefficient of variation (c.v.). The effect of forcing the regression through the origin is demonstrated in Table 5. It can be seen that even in those cases where forcing the regression through the origin is rejected by the F test, the loss of precision if the lines are forced through the origin, despite the F test, is minimal. Multiplication of c.v. with the value of Student's $\mathrm{t}$ test gives an estimate of the relative error size. For $\mathrm{P}<0.05$ and $\mathrm{n}$ between 43 and $73, \mathrm{t}$ approximately equals 2.0 . This implies that for the highest value of the c.v. in Table $5,95 \%$ of all leaves, at $\bar{X}$, have a corresponding $\mathrm{Y}$ value less than $1.70 \%(2.0 \times 0.85)$ away from their predicted value.

It is concluded that forcing the regression lines through the origin has very little effect on the precision (Table 5) even when forcing the lines through the origin was statistically rejected. Therefore in most practical circumstances it will be acceptable to take the intercept as zero.

The regression lines were computed as calibration lines. To be able to use these regressions for their ultimate use (i.e. to estimate the leaf area from their length $x$

Table 5. The effects of forcing the regression through the origin on the factor of determination $\left(\mathbf{R}^{2}\right)$ and on the coefficient of variation (c.v.) for regressions which may and for those which may not be forced through the origin.

\begin{tabular}{|c|c|c|c|c|}
\hline & \multicolumn{2}{|c|}{$\begin{array}{l}\text { With intercept }(y=a+b x) \\
\text { testing the regression through } \\
\text { the origin }\end{array}$} & \multicolumn{2}{|c|}{$\begin{array}{l}\text { Through origin }(y=b x) \\
\text { testing the regression through } \\
\text { the origin }\end{array}$} \\
\hline & not rejected & rejected & not rejected & rejected \\
\hline $\mathbf{R}^{2} \%$ & 96.44 & 97.48 & 96.37 & 97.06 \\
\hline c.v. $\%$ & 0.85 & 0.78 & 0.77 & 0.78 \\
\hline
\end{tabular}


H. VAN ARKEL

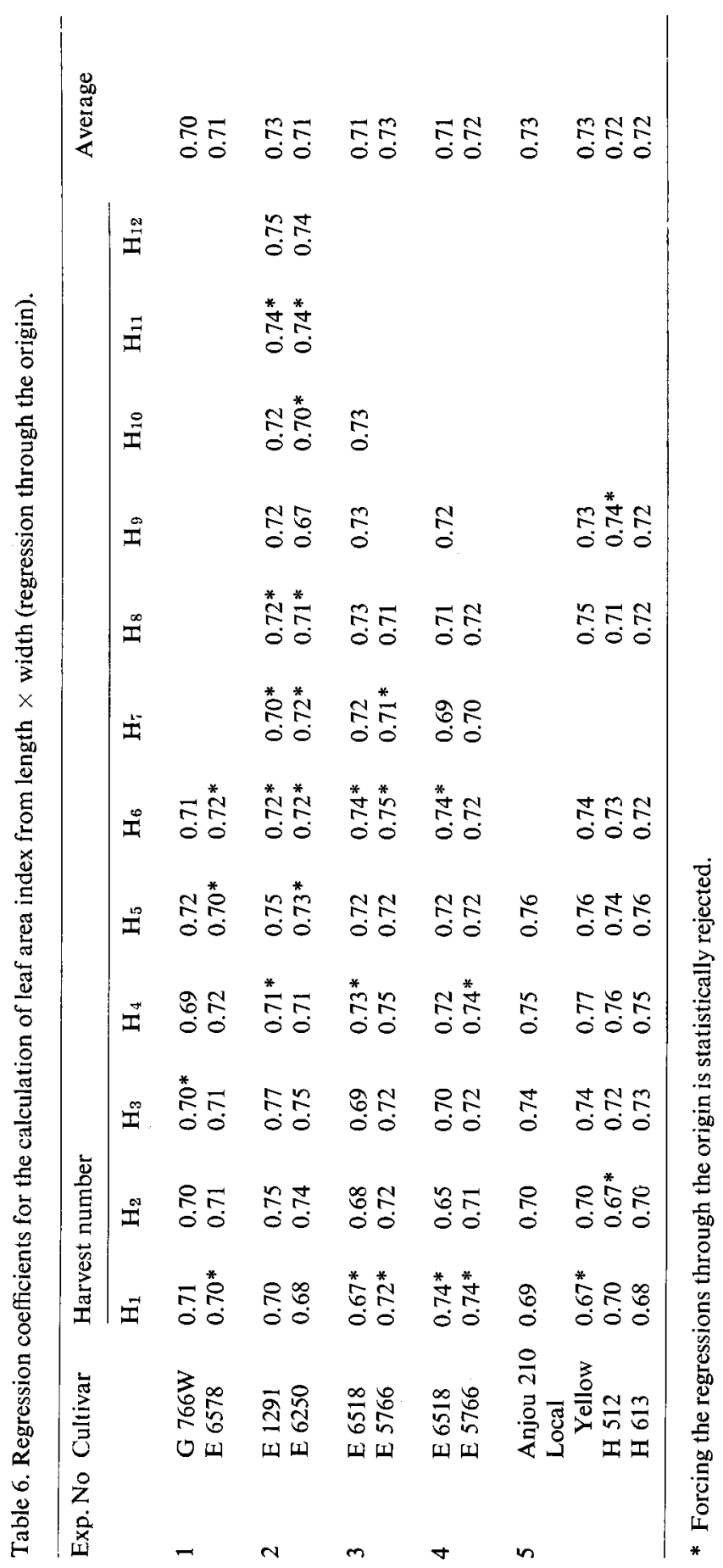


width) they must be divided by 1 . These final regression coefficients are shown in Table 6.

\section{Discussion}

It appeared that the length-width method was a reliable and accurate method for the estimation of the leaf area. If the data from replicates and plant populations were pooled, 100 different regressions could be computed. The accuracy of the method is indicated by the factor of determination (i.e. $r^{2} \times 100$ ) which is the percentage of the total variability of the length $\times$ width which is explained by leaf area. Of 7 regressions the variability in length $\times$ width was explained by leaf area at a rate of $93.7 \%$ to $96 \%$. Of 38 regressions, length $\times$ width variability was explained by leaf area at the rate of 96 to $98 \%$, and of the remaining 55 regressions more than $98 \%$ of the variability was explained by leaf area (data not presented in tables).

The accuracy of the method suggests that the number of leaves taken for each regression (varies from 45 - 75) could have been reduced. Exact calculations of the effect of sample number reduction on the precision of the regression lines would lead us beyond the scope of this paper.

The good fit of the observations to the regression lines is partly responsible for the fact that pooling harvests or cultivars was statistically rejected. Despite this it can be deduced from Table 6 that if harvests had been pooled, errors in the estimation of leaf area for a particular harvest would have been small. The largest error would have occured at harvest 2 for ' $E$ 6518' in Experiment 4. Here a regression coefficient of 0.71 would have replaced the correct 0.65 resulting in an overestimation of the leaf area by $8.5 \%$. Similarly it can be shown that the largest error in maize would have been an overestimation of $8.2 \%$ for harvest 1 of 'Local Yellow'. Pooling cultivars per harvest per trial would have resulted in even smaller mistakes. Experiment 4, harvest 2, would have shown the largest deviation with an over- or under-estimation of $4.4 \%$ for ' $\mathrm{E}$ 6518' and ' $\mathrm{E} 5766$ ', respectively.

The results of these experiments agree with those of Montgomery (1911) and Stickler et al. (1961) who also found it permissible to force the regressions through the origin. The results of the present experiments, however, show that a single regression coefficient for different cultivars and different harvests as suggested by the two workers mentioned above, represents an over-simplification if accurate readings are needed. Stickler et al. (1961) made the comment that a large proportion of the variability in the regression coefficient was due to leaf position but they made no connection with leaf age and therefore with time of harvest. This study partly accounts for the variability between leaf positions because in the earlier harvests relatively more leaves of a lower position were present, while in the later harvests mainly upper leaves were studied, due to leaf drop of lower leaves.

\section{Acknowledgment}

I am grateful to Professor L. C. A. Corsten of the Department of Mathematics of the Agricultural University of Wageningen for his advice on the use of statistical 
procedures. Thanks are also due to the Central Bureau of Statistics of the Ministry of Finance and Planning in Nairobi for letting me make use of their computer installation. This paper is published with the permission of the Director of Research, Ministry of Agriculture, Nairobi, Kenya, of the FAO and of the UNDP.

\section{References}

Arkel, H. van, 1977. New forage crop introductions for the semi-arid highland areas of Kenya as a means to increase beef production. Neth. J. agric. Sci. 25 (3) 135-150.

Arkel, H. van, 1978. Fertilizer response of cold-tolerant sorghum under semi-arid high-altitude conditions. Neth. J. agric. Sci. 26 (3) 312-325.

Darrow, G. M., 1932. Methods of measuring strawberry leaf areas. Pl. Physiol. 7: 745-747.

Davis, J. P., 1940. The relationship between leaf area and yield of the field bean with a statistical study of methods for determining area. J. Am. Soc. Agron. 32: 323-329.

Jani, T. C. \& D. K. Misra, 1966. Leaf area estimation by direct linear measurements in Ricinus communis. Nature 212: 741-742.

Montgomery, E. G., 1911. Correlation studies of corn. Rep. Nebr. agric. Exp. Stn.

Owen, P. C., 1968. A measuring scale for areas of cereal leaves. Exp. Agric. 4: 275-278.

Palaniswamy, K. M. \& K. A. Gomez, 1974. Length-width method for estimating leaf area of rice. Agron. J. 66 (3) 430-433.

Steel, R. G. D. \& J. H. Torrie, 1960. Principles and Procedures of Statistics. McGraw-Hill, London.

Stickler, F. C.; S. Wearden \& A. W. Pauli, 1961. Leaf area determination in grain sorghums. Agron. J. 53: 187-188.

Spencer, R., 1962. A rapid method for estimating leaf area of cassava using linear measurements. Trop. Agric. 39 (2) 147-152.

Watson, D. J., 1937. The estimation of leaf areas in field crops. J. agric. Sci. 27: 474-483.

Zar, J. H., 1974. Biostatistical analysis. Prentice Hall, London. 